\title{
GAMBARAN FAKTOR KELENGKAPAN PENCATATAN BUKU KESEHATAN IBU DAN ANAK (KIA) OLEH BIDAN DI PUSKESMAS DI KOTA KUPANG PROVINSI NUSA TENGGARA TIMUR
}

\author{
Meske Krull*, Dian Kurniasari \\ Program Studi Kesehatan Masyarakat, Fakultas Kedokteran, Universitas Udayana \\ *email: meske86krull@gmail.com
}

\begin{abstract}
ABSTRAK
Buku kesehatan Ibu dan anak (KIA) merupakan buku pedoman yang dimiliki oleh Ibu dan anak, yang berisi informasi dan catatan ibu dan anak. Penelitian ini bertujuan untuk untuk mengetahui Gambaran Faktor Kelengkapan pencatatan buku KIA oleh bidan di Puskesmas di Kota Kupang, Provinsi Nusa Tenggara Timur. Penelitian ini adalah penelitian deskritip dan dilaksanakan di Kota Kupang, Provinsi Nusa Tenggara Timur ,dilakukan dari bulan Februari sampai Juni 2019, dengan pendekatan cross sectional dimana jumlah sampel 65 bidan diambil per Probablity Proportional to Size di 4 tempat pelayanan kesehatan yaitu Puskesmas Oepoi, Bakunase, Oesapa dan Manutapen. Pengumpulan data primer dilakukan dengan pengisian kuisioner oleh bidan, berisikan pertanyaan terkait dengan identitas responden, pengetahuan, sikap, pelatihan dan supervisi bidan terhadap pencatatan buku KIA. Data dianalisis menggunakan statistical package for social science secara deskritip. Hasil penelitian menunjukkan pencatatan buku KIA tidak lengkap (52,3\%), Pengetahuan bidan kurang $(78,5 \%)$, semua bidan memiliki sikap positif dan pernah mendapatkan pelatihan tentang kelengkapan buku KIA $(100,0 \%)$ dan supervisi bidan dalam upaya kelengkapan pencatatan buku KIA sudah berjalan baik (96,9\%)Saran yaitu Bidan harus meningkatkan kepatuhan dalam melengkapi buku KIA mengingat manfaat dari buku KIA sangat penting dalam memberikan pelayanan.
\end{abstract}

Kata kunci : Kelengkapan buku KIA, Pengetahuan, Sikap, Pelatihan dan Supervisi

\section{ABSTRACT}

Mother and child health book $(\mathrm{MCH})$ is a guidebook owned by mother and child, which contains information and notes on mother and child. This study aims to determine the description of the completeness of the $\mathrm{MCH}$ book recording by midwives at the Puskesmas in Kupang City, East Nusa Tenggara Province.This research is a descriptive study and was carried out in Kupang City, East Nusa Tenggara Province, conducted from February to June 2019, with a cross sectional approach in which a sample of 65 midwives was taken per Probablity Proportional to Size in 4 health care centers namely Oepoi Health Center, Bakunase, Oesapa and Manutapen. Primary data collection is done by filling out the questionnaire by midwives, containing questions related to the identity of respondents, knowledge, attitudes, training and supervision of midwives on the recording of $\mathrm{MCH}$ books. Data were analyzed using descriptive statistical packages for social science. The results showed that the recording of $\mathrm{MCH}$ books was incomplete (52.3\%), knowledge of midwives was lacking (78.5\%), all midwives had a positive attitude and had received training on completeness of $\mathrm{MCH}$ books $(100.0 \%)$ and midwives supervision in completing the effort KIA book recording has been going well (96.9\%). The suggestion is that midwives should increase compliance in completing the $\mathrm{MCH}$ handbook, considering the benefits of the

$\mathrm{MCH}$ handbook are very important in providing services.

Keywords: Completeness of the MCH handbook, Knowledge, Attitude, Training and Supervision

\section{PENDAHULUAN}

Berdasarkan data Kementerian

Kesehatan Republik Indonesia, Angka

Kematian Ibu sebesar 359 orang per 100.000 kelahiran hidup pada tahun 2017
(Kemenkes RI, 2017). Data angka kematian ibu di Kecamatan Kelapa Lima, Kota Kupang, Provinsi Nusa Tenggara Timur tahun 2017 sebesar 126,55/100.000 
Vol. 7 No. 2 : 48 - 63

Kelahiran hidup, mengalami peningkatan bila dibandingkan dengan angka kematian ibu pada tahun 2016 sebesar 118,62/100.000 kelahiran hidup (Dinas Kesehatan Kota Kupang, 2017). Masih tingginya angka kematian bayi dan ibu yang merupakan indikator kesehatan umum dan kesejahteraan masyarakat, menunjukkan bahwa tujuan Sustainable Development Goals (SDGs) yaitu menurunkan jumlah kematian ibu yang terkait dengan masa kehamilan, persalinan, dan nifas di bawah 70 orang per 100.000 kelahiran hidup pada tahun 2030 (Kemenkes RI, 2012) akan sulit tercapai.

Tingginya angka kematian ibu juga menunjukkan kualitas pelayanan antenatal petugas kesehatan (Supanik, 2011). Dalam pelayanan antenatal, dokumentasi merupakan bagian penting dari kegiatan bidan setelah memberikan pelayanan antenatal (Prawirohardjo, Sarwono 2008). Dokumentasi tersebut mempunyai porsi besar dalam catatan klinis pasien yang menginformasikan faktor atau situasi tertentu selama asuhan kebidanan diberikan yang meliputi kondisi kesehatan pasien, kebutuhan pasien, rencana asuhan, kegiatan asuhan kebidanan serta respon pasien terhadap asuhan yang telah diterima. Frekuensi pemeriksaan kesehatan ibu hamil tersebut dicatat secara menyeluruh dan berkesinambungan dalam Buku Kesehatan Ibu dan Anak (KIA) dan dipegang oleh ibu atau keluarga. Buku KIA memberikan informasi, edukasi dan komunikasi mengenai kesehatan ibu dan anak dan merupakan penghubung antara tenaga kesehatan dan ibu dan anak yang berkaitan dengan catatan imunisasi, penyakit dan masalah perkembangan anak sehingga berperan dalam memberikan edukasi kepada keluarga dalam menghadapi tanda bahaya kehamilan, persalinan, dan nifas (IBI, 2010). Bidan wajib memberikan Buku KIA kepada setiap ibu hamil satu buku KIA pada kunjungan antenatal care (ANC) yang pertama (K1) baik di posyandu atau puskesmas dan memberikan penjelasan tentang manfaat buku KIA untuk mengingatkan ibu hamil agar membaca informasi yang ada dalam buku KIA, dan juga dapat menciptakan hubungan yang lebih dekat antara ibu hamil dan bidan, serta bidan juga wajib mencatat informasi kesehatan dari ibu hamil.

Pada pelaksanaannya, masih ada bidan yang tidak menerapkan pencatatan informasi kesehatan yang mendetail sesuai dalam buku Kesehatan Ibu dan Anak (KIA). Menurut hasil penelitian Kartika (2013), pencatatan pada buku KIA di Puskesmas Boyolali hanya dilakukan terhadap apa yang diobservasi oleh bidan dan yang dianggap penting untuk mempersingkat waktu. Peneliti menemukan adanya pencatatan yang tidak lengkap pada anamnesa sebesar $70 \%$ dan tabel ANC sebesar 5\%. Penelitian lain dilakukan oleh Rante, A, Susilo W, Faikah (2007) yang menunjukkan 12 tahun bahwa dokumentasi dalam pelayanan kebidanan dalam Aspek ANC, Intranatal care (INC) dan Postnatal care (PNC) sudah diterapkan bidan, namun untuk kelengkapan pendokumentasian masih ada yang kurang. Siswiantari (2016) dalam 
penelitiannya juga menemukan bahwa sebagian besar responden (56\%) mempunyai fungsi pencatatan buku KIA yang tidak lengkap.

Berdasarkan survey pendahuluan yang dilakukan bulan Desember tahun 2018, hasil studi dokumentasi terhadap 10 buku KIA di wilayah kerja Puskesmas Kelapa Lima menunjukkan dari 10 buku ada 7 buku yang tidak lengkap. Pada lembar anamnesa ditemukan ketidak lengkapan dalam penulisan alamat rumah/ nomor telepon sebesar 20\% dan pada lembar pemeriksaan fisik ditemukan ketidak lengkapan dalam pengukuran Lingkaran Lengan Atas (LILA) sebesar 35\%. Catatan Anamnese dalam dokumen pelayanan kesehatan merupakan pencatatan yang sangat penting karena merupakan data atau informasi tentang permasalahan yang sedang dialami atau dirasakan oleh pasien (Hasanah, 2012). Sedangkan pemeriksaan fisik berguna untuk mengumpulkan data tentang kesehatan pasien, menambah informasi, menyangkal data yang diperoleh dari riwayat pasien, mengidentifikasi masalah pasien, menilai perubahan status pasien, dan mengevaluasi pelaksanaan tindakan yang telah diberikan. Konsistensi dalam penggunaan dan penyebaran serta promosi buku KIA sebagaimana fungsi dan kelebihannya dapat meningkatkan pengetahuan, perilaku ibu hamil serta meningkatkan persalinan normal dan aman serta meningkatkan kesehatan anak (Syafiq,A, Fikawati S. 2007).

Siswiantari (2016) menemukan bahwa faktor terbesar dari ketidak lengkapan pencatatan buku KIA oleh bidan adalah bidan yang kurang sabar dalam pendokumentasian sehingga mengakibatkan 19 buku KIA tidak tercatat lembar anamneses $(37,26 \%)$ dan 16 buku tidak tercatat lembar pemeriksaan fisik (31,37\%). Pada penelitian lain, Kartika (2013) menemukan bahwa faktor ketidaklengkapan pencatatan juga disebabkan oleh bidan yang kurang sabar dan terburu-buru dalam mengisi buku KIA sehingga bidan juga menulis apa yang dianggap paling penting saja dalam mengisi item yang ada di buku KIA (N2, N3 dan N4). Sedangkan Cahyani (2016) menyimpulkan bahwa faktor ketidak lengkapan pencatatan buku KIA adalah masa kerja, ketrampilan, beban kerja, motivasi, dan penghargaan.

Berdasarkan masalah tersebut di atas, maka penulis ingin mengetahui pengetahuan, sikap, pelatihan dan supervisi dalam upaya pencatatan buku KIA di Puskesmas di Kota Kupang Provinsi Nusa Tenggara Timur. Hal ini penting untuk diketahui agar hasil penelitian yang didapat nantinya bisa memberikan informasi yang berguna bagi pihak puskesmas, sehingga petugas kesehatan di puskesmas dapat melakukan pencatatan buku KIA secara baik dan benar dan juga dapat dimanfaatkan dalam pengembangan bidang kesehatan ibu dan anak.

\section{METODE PENELITIAN}

Jenis penelitian ini menggunakan desain penelitian kuantitatif dengan pendekatan cross-sectional. Rancangan ini berarti peneliti melakukan observasi atau pengukuran terhadap variabel bebas dan 
Vol. 7 No. 2 : 48 - 63

variabel tergantung dilakukan sekali dalam waktu yang bersamaan.

Penelitian ini dilaksanakan di Puskesmas Kota Kupang, Provinsi Nusa Tenggara Timur dan dilakukan dari Bulan Februari sampai Bulan Juni 2019.

Populasi target pada penelitian ini adalah seluruh bidan yang bekerja di Puskesmas di Kota Kupang, Provinsi Nusa Tenggara Timur. Populasi terjangkau dalam penelitian ini adalah bidan yang bekerja di poli KIA di puskesmas di Kota Kupang.

Sampel dipilih berdasarkan kriteria inklusi yaitu bidan puskesmas yang bersedia menjadi responden. Pemilihan sampel dalam penelitian ini akan dilakukan menggunakan teknik cluster sampling. Kota Kupang memiliki 11 puskesmas. Sampel puskesmas akan dipilih dengan metode Probablity Proportional to Size (pps) dari 11 puskesmas tersebut. Sampel individu bidan di poli KIA yang ada di puskesmas tersebut akan dipilih secara acak sederhana.

Jenis data yang dikumpulkan dalam penelitian ini adalah data primer. Pengumpulan data primer dilakukan observasi dengan pengisian kuisioner oleh bidan. Kuisioner berisikan pertanyaan terkait dengan identitas responden, pengetahuan, sikap, pelatihan dan supervisi bidan terhadap pencatatan buku KIA. Responden harus menandatangani informed consent sebelum bersedia di wawancarai dan setelah itu peneliti membacakan langkah menjawab sesuai instrumen. Pengisian kuesioner oleh responden didampingi oleh peneliti untuk mengantisipasi kuesioner yang kurang dipahami oleh responden. Setelah selesai melakukan pengumpulan data, data yang didapatkan kemudian dicek oleh peneliti. Selain itu peneliti juga melakukan analisis buku KIA yang telah dicatat oleh responden.

\section{HASIL DAN DISKUSI}

Hasil penelitian ini menunjukkan bahwa dari 65 responden sebagian besar pencatatan buku KIA tidak lengkap yaitu sebanyak 34 orang $(52,3 \%)$, terdapat pencatatan buku KIA tidak lengkap di Puskesmas di Kota Kupang, Provinsi Nusa Tenggara Timur. Ketidaklengkapan pencatatan buku KIA terbesar ada pada penulisan identitas keluarga, dimana hasil observasi pada buku KIA sebagian besar petugas tidak menulis identitas suami atau keluarga yaitu $43.1 \%$ identitas keluarga yang sering tidak di isi seperti nama suami, alamat lengkap, nomor telp, agama dan pekerjaan. Beberapa point yang tidak dilengkapi oleh petugas seperti catatan menyambut persalinan, catatan kesehatan ibu hamil dan penempelan stiker P4K namun ketidak lengkapan tersebut hanya dilakukan oleh sebagian kecil responden. Hasil penelitian ini didukung oleh hasil penelitian terdahulu yang menunjukkan hasil yang sama seperti penelitian Kartika (2013), menemukan adanya pencatatan yang tidak lengkap pada anamnesa sebesar $70 \%$ dan tabel ANC sebesar 5\%. Penelitian Rante,dkk (2017) yang menunjukkan bahwa dokumentasi dalam pelayanan kebidanan dalam Aspek ANC, Intranatal care (INC) dan Postnatal care (PNC) sudah diterapkan bidan, namun untuk kelengkapan pendokumentasian masih 
ada yang kurang. Penelitian Siswiantari (2016) juga menemukan bahwa sebagian besar responden (56\%) mempunyai fungsi pencatatan buku KIA yang tidak lengkap.

Ketidak lengkapan pencatatan buku KIA di Puskesmas di Kota Kupang, Provinsi Nusa Tenggara Timur yang artinya belum memenuhi standar pendokumentasian kebidanan yang baik. Bidan menyatakan, mengisi item yang dianggap paling penting saja untuk mempersingkat waktu, dan bagian yang kosong akan diisi pada kunjungan pasien berikutnya. Namun pendokomentasian pada kunjungan - kunjungan berikutnya masih tidak lengkap karena sikap bidan yang menyatakan bahwa wajar apabila ada data di buku KIA yang kurang lengkap, karena seringkali terlalu banyak pasien dan proses pencatatan menyita waktu. Ketidaklengkapan pencatatan buku KIA terbanyak ada pada penulisan identitas suami atau keluarga penanggung jawab seperti nama suami, alamat lengkap, nomor telpon, agama dan pekerjaan. Hal ini tidak sesuai dengan teori Mufdillah (2012), yang menyatakan bahwa semua catatan buku KIA, wajib diisi dengan lengkap, karena semua data yang ada pada buku KIA saling berhubungan serta memiliki makna medis dan data tersebut sudah sangat informatif sehingga dapat membantu deteksi sedini mungkin adanya penyulit dalam kehamilan.

Dampak yang ditimbukan akibat ketidaklengkapan pencatatan buku KIA adalah informasi tentang kesehatan ibu hamil dapat terputus, ketidaklengkapan tentang identitas penanggung jawab khususnya suami dapat mempersulit petugas untuk memberikan informasi dan edukasi yang terkait tentang perawatan ibu hamil dan ibu pasca bersalin. Selain itu ketidaklengkapan pencatatan buku KIA sangat mempengaruhi kualitas pelayanan di puskesmas yang tidak sesuai standar yang telah ditetapkan.

Buku KIA diberikan pada ibu pada saat pertama kali memeriksakan kehamilannya dan selanjutnya buku tersebut dibawa ibu untuk disimpan dirumah. Petugas kesehatan akan mencatat setiap pelayanan yang diberikan pada ibu dan anak dengan lengkap di buku KIA, agar ibu dan keluarga lainnya dapat mengetahui dengan pasti kesehatan ibu dan anak. Petugas juga menganjurkan kepada ibu agar setiap kontrol ulang untuk membawa buku KIA agar bidan dapat mengisi dengan lengkap setelah melakukan pelayanan antenatal. Buku KIA yang diisi lengkap akan memudahkan bidan untuk mendeteksi sedini mungkin adanya risiko atau masalah yang terjadi pada kehamilan dan mengetahui perkembangan serta pertumbuhan balita (Depkes RI dan JICA.a. 2009).

Pentingnya kelengkapan pencatatan buku KIA yaitu untuk mengetahui catatan perkembangan kesehatan yang lengkap sejak ibu melahirkan sampai anaknya berusia lima tahun. Manfaat lain dari pencatatan buku KIA adalah menjadi pedoman untuk petugas dalam mengambil keputusan medis terhadap ibu nifas dan dapat mendeteksi secara dini jika terjadi penyulit dalam kehamilan (Mufdillah, 
2012). Tujuan utama pencatatan adalah menentukan sekiranya ada kekurangan agar dapat dikoreksi segera saat pasien masih dirawat atau item kekurangan sebelum petugas yang mengisi rekam medis lupa, hal ini dilakukan untuk menjamin efektifitas rekam medis, antara lain rekam kesehatan dapat berkesinambungan.

Tabel 1. Karakteristik Responden.
Frekuensi (n)

Persentase (\%)

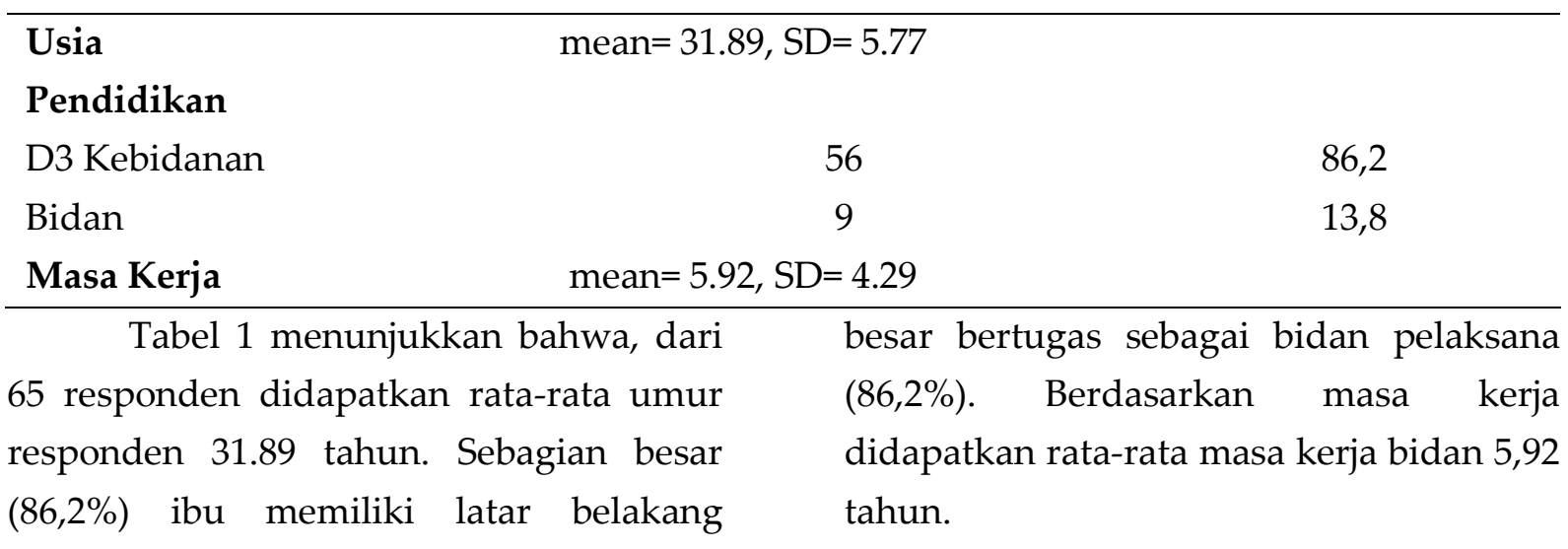
pendidikan D3 Kebidanan dan sebagian

Tabel 2. Distribusi Frekuensi Kelengkapan Pencatatan Buku KIA di Puskesmas di Kota Kupang Provinsi Nusa Tenggara Timur.

\begin{tabular}{ccc}
\hline $\begin{array}{c}\text { Kelengkapan Pencatatan Buku } \\
\text { KIA }\end{array}$ & Frekuensi (n) & Persentase (\%) \\
\hline Lengkap & 31 & 47,7 \\
Tidak lengkap & 34 & 52,3 \\
\hline Total & $\mathbf{6 5}$ & $\mathbf{1 0 0}$ \\
\hline
\end{tabular}

Tabel 2 Menunjukkan bahwa dari 65 responden sebagian besar pencatatan buku KIA tidak lengkap yaitu sebanyak 34

\section{Karakteristik Responden}

Responden dalam penelitian ini adalah bidan yang bekerja di poli KIA sebanyak 65 orang. Karakteristik responden meliputi usia, pendidikan, unit kerja dan masa kerja yang disajikan pada tabel 1. dibawah ini : 


\begin{tabular}{llcc}
\hline 1 & Identitas keluarga & $37(56,9)$ & $28(43,1)$ \\
2 & Menyambut Persalinan (Amanat & $61(93,8)$ & $4(6,2)$ \\
& $\begin{array}{l}\text { Persalinan) } \\
3\end{array}$ & $\begin{array}{l}\text { Stiker P4K diisi dan ditempelkan } \\
\text { dirumah ibu hamil }\end{array}$ & $63(96,9)$ \\
4 & Catatan Kesehatan Ibu Hamil & $62(95,4)$ & $3(4,6)$ \\
\hline
\end{tabular}

Tabel 3 Menunjukkan sebagian besar ketidaklengkapan pencatatan buku KIA ada pada penulisan identitas keluarga yaitu 28 orang $(43,1 \%)$, menyambut persalinan (amanat persalinan) 4 orang (6,2\%), Stiker P4K diisi dan ditempelkan dirumah ibu hamil 2 orang $(3,1 \%)$ dan catatan kesehatan ibu hamil 3 orang $(4,6 \%)$. Identitas keluarga yang sering tidak diisi seperti nama suami, alamat lengkap, nomor telpon, agama dan pekerjaan begitu juga tentang menyambut persalinan, stiker P4K dan catatan kesehatan ibu hamil.

Tabel 4. Distribusi Frekuensi Tingkat Pengetahuan Bidan Tentang Kelengkapan Pencatatan Buku KIA di Puskesmas di Kota Kupang Provinsi Nusa Tenggara Timur.

\begin{tabular}{ccc}
\hline Tingkat Pengetahuan & Frekuensi (n) & Persentase (\%) \\
\hline Baik & 14 & 21,5 \\
Kurang & 51 & 78,5 \\
\hline Total & $\mathbf{6 5}$ & $\mathbf{1 0 0}$ \\
\hline
\end{tabular}

Tabel 4 Menunjukkan dari 65 responden sebagian besar responden memiliki tingkat pengetahuan yang kurang tentang kelengkapan pencatatan buku KIA yaitu sebanyak 51 orang $(78,5 \%)$ dan yang baik cuma 14 orang $(21,5 \%)$.

Tabel 5. Distribusi Frekuensi Jawaban Kuesioner Tingkat Pengetahuan Bidan Tentang Kelengkapan Pencatatan Buku KIA di Puskesmas di Kota Kupang Provinsi Nusa Tenggara Timur $(n=65)$.

\begin{tabular}{|c|c|c|c|}
\hline No & Pertanyaan & $\begin{array}{c}\text { Pengetahuan } \\
\text { Baik }(\geq 75 \%) \\
\text { n (\%) }\end{array}$ & $\begin{array}{c}\text { Pengetahuan Kurang } \\
(<75 \%) \\
\text { n ( } \%)\end{array}$ \\
\hline 1 & Apa itu buku KIA & $14(21,5)$ & $51(78,5)$ \\
\hline 2 & $\begin{array}{l}\text { Apakah ibu tahu apa saja yg perlu diisi } \\
\text { di buku KIA oleh bidan terkait } \\
\text { informasi ibu hamil }\end{array}$ & $3(4,6)$ & $62(95,4)$ \\
\hline 3 & Apakah tujuan pengisian Buku KIA & $5(7,7)$ & $60(92,3)$ \\
\hline
\end{tabular}


4 Apakah manfaat pengisian Buku KIA

$3(4,6)$

$11(16,9)$

$1(1,5)$

$8(12,3)$

$14(21,5)$

$15(23,1)$

$13(20,0)$

$16(24,6)$

$1(1,5)$
$62(95,4)$

$54(83,1)$

$64(98,5)$

$57(87,7)$

$51(78,5)$

$50(76,9)$

$52(80,0)$

$49(75,5)$

$3(4,6)$

12 Apa yang dilakukan bila ibu hamilmenghilangkan buku KIA

Tabel 5 Menunjukkan bahwa dari 65 responden sebagian besar responden memiliki pengetahuan yang kurang tentang apa itu buku KIA yaitu sebanyak 51 orang $(78,5 \%)$, apakah ibu tahu apa saja yang perlu diisi di buku KIA oleh bidan terkait informasi ibu hamil 62 orang $(95,4 \%)$, apakah tujuan pengisian buku KIA 60 orang $(92,3 \%)$, apakah manfaat pengisian buku KIA 62 orang (95,4\%), siapa sasaran langsung dari buku KIA 54 orang $(83,1 \%)$, siapa sasaran tidak langsung dari buku KIA 64 orang (98,5\%), siapa yang patut mengisi buku KIA 57 orang $(87,7 \%)$, bagaimana pencatatan dilakukan bila ibu datang tidak membawa buku KIA 51 orang (78,5\%), kapan pencatatan sebaiknya dilakukan 50 orang (76,9\%), apa dampak bila pencatatan buku KIA ibu hamil tidak lengkap 52 orang (80\%), urutkan pencatatan buku KIA kepada ibu hamil yang benar 49 orang (75,5\%), dan apa yang dilakukan bila ibu hamil menghilangkan buku KIA 3 orang $(4,6 \%)$.

Tabel 6. Distribusi Frekuensi Sikap Bidan Terhadap Kelengkapan Pencatatan Buku KIA di Puskesmas di Kota Kupang Provinsi Nusa Tenggara Timur (n= 65).

\begin{tabular}{ccc}
\hline Sikap & Frekuensi (n) & Persentase (\%) \\
\hline Positif & 65 & 100,0
\end{tabular}

Berdasarkan Hasil tabel 6 di atas

Menunjukkan dari 65 responden semua responden $(100 \%)$ memiliki sikap yang positif terhadap kelengkapan pencatatan buku KIA.

Tabel 7. Distribusi Frekuensi Jawaban Kuesioner Sikap Bidan Terhadap Kelengkapan Pencatatan Buku KIA di Puskesmas di Kota Kupang Provinsi Nusa Tenggara Timur ( $n=65)$

\begin{tabular}{|c|c|c|c|}
\hline No & & Pernyataan & $\begin{array}{c}\text { STS } \\
\text { n (\%) }\end{array}$ \\
\hline 1 & Menurut & buku & $0(0)$ \\
\hline
\end{tabular}


merupakan buku pegangan yang harus dibawa ibu hamil.

2 Menurut saya, buku KIA diperlukan dalam pelayanan ibu hamil.

3 Menurut saya, buku KIA harus dicatat setiap kali ibu hamil datang ke pelayanan kesehatan.

4 Menurut saya, pendataan yang benar tentang ibu hamil adalah tanggung jawab semua (bidan, keluarga/ibu hamil dan kader).

6 Menurut saya, pencatatan buku KIA harus dilakukan segera setelah pengkajian pertama dan selesai melakukan setiap langkah asuhan kebidanan.

7 Menurut saya, untuk mempersingkat waktu tidak masalah untuk mengisi item yang dianggap paling penting saja pada buku KIA untuk ibu hamil.

8 Menurut saya wajar apabila ada data di Buku KIA yang kurang lengkap, karena seringkali terlalu banyak pasien dan proses mencatat menyita waktu.

9 Menurut saya, tidak perlu mengoreksi data pada Buku KIA bila ada data yang tidak lengkap diisi dari pemeriksaan sebelumnya.

10 Menurut saya, tidak masalah pencatatan ibu hamil tidak lengkap untuk satu atau dua kali kunjungan.

11 Menurut saya, apabila tidak ada keluhan dari ibu hamil, maka kolom keluhan dibiarkan kosong.

12 Menurut saya, perlu waktu yang cukup lama untuk memastikan bahwa buku KIA dicatat dengan lengkap.

13 Menurut saya, jika ibu hamil tidak membawa buku KIA maka pencatatan dapat dilakukan saat pasien berkunjung berikutnya.

14 Menurut saya, jika ibu hamil tidak

$\begin{array}{cccc}0(0) & 65(100) & 0(0) & 0(0) \\ 65(100) & 0(0) & 0(0) & 0(0) \\ 0(0) & 65(100) & 0(0) & 0(0) \\ & & & \\ 0 & 65(100) & 0 & 0 \\ (0) & & (0) & (0) \\ & & & \\ & & & \\ 0 & 0 & 65(100) & 0 \\ (0) & (0) & & (0) \\ & & & \\ & & & \\ 0 & & & \\ (0) & (0) & (96,9) & \end{array}$

0

(0)

(0) $\quad(98,5)$

0

0

$2(3,1)$

63

(0) (0)

$(96,3)$

$1(1,5) \quad 64(98,5)$

0

0

0

0

64

(0)

(0)

$(98,5)$

0

(0)

(0)

64

$(98,5)$

63 
Vol. 7 No. 2 : 48 - 63

membawa buku KIA, pelayanan

(0)

$(96,9)$

tidak diberikan kepada ibu hamil tersebut.

15 Menurut saya, buku KIA berguna untuk memantau kesehatan ibu hamil secara intensif dan terus menerus

Tabel 7 Menunjukkan dari 65 responden sebagian besar responden menjawab sangat setuju terhadap buku KIA harus dicatat setiap kali ibu hamil datang ke pelayanan kesehatan $(100,0 \%)$ dan pernyataan buku KIA berguna untuk memantau kesehatan ibu hamil secara intensif dan terus menerus (96,9\%). Sebagian besar responden setuju terhadap pernyataan buku KIA merupakan buku pegangan yang harus dibawa ibu hamil, buku KIA diperlukan dalam pelayanan ibu hamil, ibu hamil adalah tanggung jawab semua (bidan, keluarga/ibu hamil dan kader), pencatatan buku KIA harus dilakukan segera setelah pengkajian pertama dan selesai melakukan setiap langkah asuhan kebidanan (100,0\%), buku KIA tidak harus diisi secara lengkap pada bagian identitas, alamat, nomor telepon ibu hamil dan keluarga dan apabila tidak ada keluhan dari ibu hamil, maka kolom keluhan dibiarkan kosong (98,5\%).
Sebagian besar responden tidak setuju terhadap pernyataan untuk mempersingkat waktu tidak masalah untuk mengisi item yang dianggap paling penting saja pada buku KIA untuk ibu hamil (100,0\%), wajar apabila ada data di Buku KIA yang kurang lengkap, karena seringkali terlalu banyak pasien dan proses mencatat menyita waktu $(96,9 \%)$, tidak perlu mengoreksi data pada Buku KIA bila ada data yang tidak lengkap diisi dari pemeriksaan sebelumnya, perlu waktu yang cukup lama untuk memastikan bahwa buku KIA dicatat dengan lengkap, jika ibu hamil tidak membawa buku KIA, pelayanan tidak diberikan kepada ibu hamil tersebut $(98,5 \%)$ dan sebagian besar responden menjawab sangat tidak setuju terhadap pernyataan tidak masalah pencatatan ibu hamil tidak lengkap untuk satu atau dua kali kunjungan (96,3\%).

Tabel 8. Distribusi Frekuensi Pelatihan Bidan Terkait Kelengkapan Pencatatan Buku KIA di Puskesmas di Kota Kupang Provinsi Nusa Tenggara Timur (n= 65)

\begin{tabular}{cccc}
\hline No & \multicolumn{1}{c}{ Pernyataan } & $\begin{array}{c}\text { Pernah } \\
\mathbf{n ~ ( \% )}\end{array}$ & $\begin{array}{c}\text { Tidak } \\
\mathbf{n}(\mathbf{\%})\end{array}$ \\
\hline 1 & $\begin{array}{l}\text { Saya pernah mengikuti pelatihan tentang } \\
\text { pencatatan } \quad 65(100)\end{array}$ & $0(0)$ \\
2 & $\begin{array}{l}\text { Senior/ rekan kerja tempat saya bekerja } \\
\text { pernah memberikan pelatihan kepada }\end{array}$ & $65(100)$ & $0(0)$
\end{tabular}


saya untuk mengisi buku KIA

3 Apabila ada bidan baru yang bekerja,

Tabel 8 Menunjukkan bahwa semua bidan pernah mendapatkan atau melakukan tindakan atau pelatihan yang terkait dengan kelengkapan pencatatan buku KIA yaitu meliputi pernah mengikuti pelatihan tentang pencatatan buku KIA 65 orang (100\%), senior/ rekan kerja tempat saya bekerja pernah memberikan pelatihan kepada saya untuk mengisi buku KIA 65 orang (100\%) dan bila ada bidan baru yang bekerja saya akan memberikan informasi dan pelatihan kepadanya cara-cara mengisi buku KIA 65 orang (100\%).

Tabel 9. Distribusi Frekuensi Supervisi Kerja Dalam Upaya Kelengkapan Pencatatan Buku KIA di Puskesmas di Kota Kupang Provinsi Nusa Tenggara Timur (n= 65)

\begin{tabular}{ccc}
\hline Supervisi Kerja & Frekuensi (n) & Persentase (\%) \\
\hline Baik & 63 & 96,9 \\
Kurang & 2 & 3,1 \\
\hline Total & $\mathbf{6 5}$ & $\mathbf{1 0 0}$ \\
\hline
\end{tabular}

Berdasarkan Hasil Tabel 9 kelengkapan pencatatan buku KIA sudah Menunjukkan dari 65 responden sebagian berjalan baik (96,9\%). besar supervisi kerja dalam upaya

Tabel 10. Distribusi Frekuensi Jawaban Supervisi Kerja Dalam Upaya Kelengkapan Pencatatan Buku KIA di Puskesmas di Kota Kupang Provinsi Nusa Tenggara Timur $(n=65)$

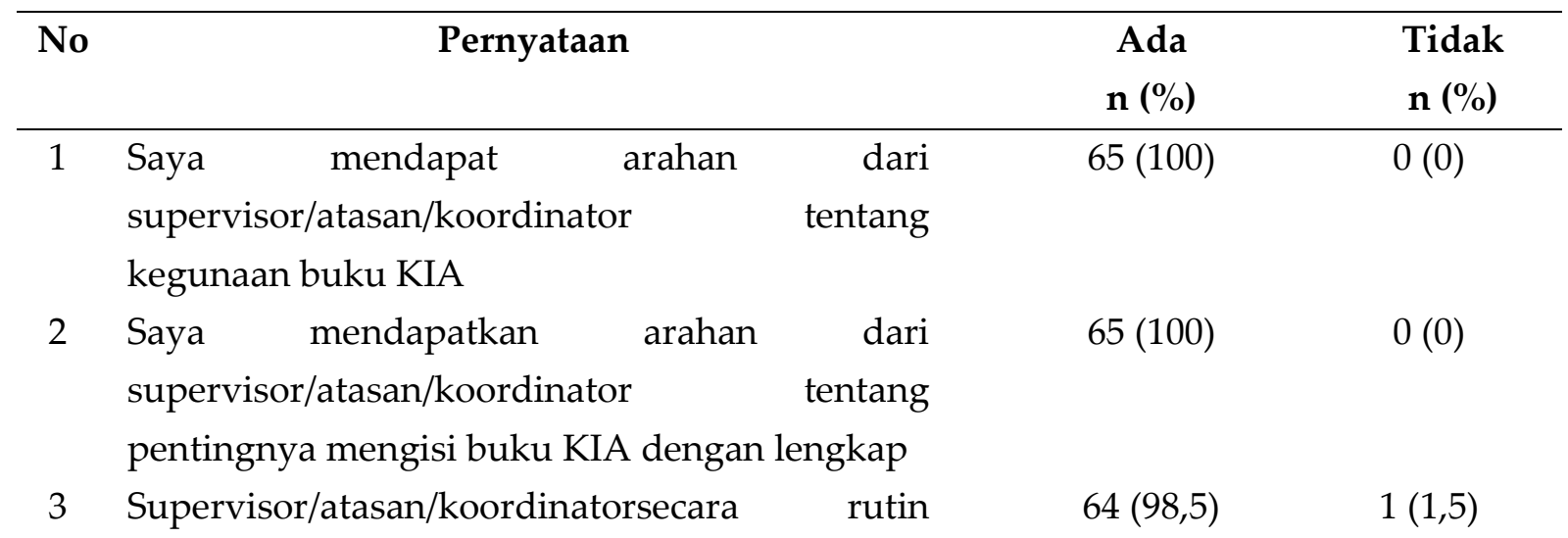


melakukan pengecekan buku KIA yang saya isi

4 Supervisor/atasan/koordinator melakukan

$64(98,5)$

evaluasi kelengkapan pengisian buku KIA secara rutin

5 Saya menyampaikan kendala yang dihadapi dalam pencatatan buku KIA kepada supervisor/atasan/coordinator

6 Saya menyampaikan pencapaian yang diraih $61(93,8)$ dalam pencatatan buku KIA kepada supervisor/atasan/coordinator

7 Supervisor/atasan/koordinator memberikan $64(98,5)$ umpan balik terhadap kendala yang dihadapi dalam pencatatan buku KIA kepada saya

\section{Supervisor/atasan/koordinator memberikan} penghargaan atas pencapaian pencatatan buku KIA yang lengkap

Hasil Tabel 10 diatas Menunjukkan sebagian besar supervisi kerja dalam upaya kelengkapan pencatatan buku KIA sudah dilaksanakan. Ada satu kegiatan supervisi yang tidak dilaksanakan oleh bidan yaitu menyampaikan kendala yang dihadapi dalam pencatatan buku KIA kepada supervisor/atasan/koordinator (96,9\%). Pencatatan tersebut diperlukan untuk memantau secara intensif dan terus menerus kondisi dan permasalahan yang ditemukan pada para ibu segera setelah bidan melakukan pelayanan (Depkes RI dan JICA.a. 2009). Buku KIA memberikan informasi, edukasi dan komunikasi mengenai kesehatan ibu dan anak dan merupakan penghubung antara tenaga kesehatan dan ibu dan anak yang berkaitan dengan catatan imunisasi, penyakit dan masalah perkembangan anak sehingga berperan dalam memberikan edukasi kepada keluarga dalam menghadapi tanda bahaya kehamilan, persalinan, dan nifas (IBI, 2010). Bidan wajib memberikan setiap ibu hamil satu buku KIA pada kunjungan antenatal care (ANC) yang pertama (K1) baik di posyandu atau di puskesmas dan memberikan penjelasan tentang manfaat buku KIA dan mengingatkan ibu hamil agar membaca informasi yang ada dalam buku KIA, menciptakan interaksi antara ibu hamil dan bidan, serta wajib mencatat informasi kesehatan dari ibu hamil.

$$
\text { Ketidaklengkapan pencatatan }
$$

buku KIA dapat dipengaruhi oleh banyak faktor. Pada penelitian ini, beberapa faktor yang digali untuk diketahui gambaran faktor yang mungkin mempengaruhi ketidaklengkapan pencatatan buku KIA antara lain pengetahuan bidan, sikap, pelatihan dan supervisi. Hasil penelitian didapatkan bahwa sebagian besar bidan memiliki tingkat pengetahuan yang kurang tentang kelengkapan pencatatan buku KIA, sikap yang positif, semua bidan 
sudah mendapatkan pelatihan dan supervisi kerja dalam upaya kelengkapan pencatatan buku KIA sebagian besar sudah dilaksanakan.

Hal yang menarik dalam penelitian ini adalah sebagian besar bidan $(78,5)$ memiliki tingkat pengetahuan yang kurang tentang kelengkapan pencatatan buku KIA. Hal ini dapat dilihat berdasarkan hasil jawaban responden dalam kuesioner, walaupun semua bidan bisa menjawab dengan benar semua pertanyaan dalam kuesioner, namun semua bidan hanya mampu memilih satu jawaban saja dari 1-10 jawaban yang tersedia, sehingga secara keseluruhan bidan memiliki tingkat pengetahuan yang kurang. Hasil penelitian ini sejalan dengan penelitian Yuyun (2015) tentang gambaran tingkat pengetahuan petugas tentang penulisan buku KIE di Puskesmas Klaten, menunjukkan dari 60 responden sebagian petugas memiliki tingkat pengetahuan yang kurang yaitu sebesar $65,5 \%$, pengetahuan baik $25,8 \%$ dan pengetahuan cukup hanya 8,7\%. Pengetahuan adalah berbagai gejala yang ditemui dan diperoleh melalui pengamatan indra. Pengetahuan muncul ketika seseorang menggunakan indera atau akal budinya untuk mengenali benda atau kejadian tertentu yang belum pernah dilihat atau dirasakan sebelumnya (Notoatmojo, S.2014).

Sikap bidan terhadap kelengkapan pencatatan buku KIA dalam penelitian ini menunjukkan semua bidan $(100,0)$ memiliki sikap yang positif terhadap kelengkapan pencatatan buku KIA. Sikap positif yang dimiliki bidan menunjukkan adanya keyakinan dalam diri bidan mengenai pentingnya kelengkapan pencatatan buku KIA. Sikap secara nyata menunjukkan konotasi adanya kesesuaian reaksi terhadap stimulus tertentu yang dalam kehidupan sehari-hari merupakan reaksi yang bersifat emosional terhadap stimulus sosial. Selain bersifat positif atau negatif, sikap memiliki tingkat kedalaman yang berbeda-beda. Sikap dapat berubah dengan diperoleh tambahan informasi tentang objek tersebut melalui persuasi serta tekanan dari kelompok sosialnya (Azwar, 2009). Ada empat alasan pokok mengapa seseorang berperilaku tertentu. Keempat hal itu adalah: pengetahuan, kepercayaan, sikap, dan orang penting sebagai referensi (Notoatmodjo,S.2014). Menurut Niven (2012) sikap terbentuk dari tiga komponen utama yaitu l) afektif yakni komponen yang berhubungan dengan perasaan/emosi seseorang akan sesuatu, 2) kognitif, berhubungan dengan kepercayaan akan suatu obyek, dan 3) perilaku yaitu tingkah laku nyata. Sikap adalah suatu kecenderungan bertindak kearah atau menolak faktor lingkungan.

Hasil penelitian ini menunjukkan walaupun semua responden memiliki sikap yang baik tentang pencatatan buku KIA, namun sebagian besar tidak lengkap dalam melakukan pencatatan buku KIA. Hal ini sesuai dengan teori yang menyatakan sikap baik tidak akan selalu diiringi dengan perilaku yang sesuai sikap yang dimiliki. Sikap menggambarkan sikap suka atau tidak suka seseorang terhadap objek. Sikap sering diperoleh dari pengalaman sendiri atau dari orang lain (Wawan,A dan Dewi,M. 2011). 
Vol. 7 No. 2 : 48 - 63

Ketidaklengkapan pencatatan buku KIA bisa juga terkait dengan pengaruh orang lain yang dianggap penting, dalam hal ini pengaruh teman kerja ketika orang lain tidak lengkap mengisi buku KIA bisa diikuti oleh petugas yang lain.

Pelatihan bidan terkait kelengkapan pencatatan buku KIA di Puskesmas Kota Kupang menunjukkan semua bidan sudah mendapatkan pelatihan, baik mengikuti pelatihan secara resmi, mendapatkan pelatihan atau bimbingan dari senior dan juga pernah memberikan pelatihan atau bimbingan kepada junior bidan yang baru bergabung di puskesmas. Hasil penelitian menunjukkan walaupun semua bidan sudah mendapatkan pelatihan, namun masih banyak ditemukan ketidaklengkapan dari pencatatan buku KIA. Pelatihan merupakan salah satu program kerja dalam mengembangkan kemampuan petugas. Pelatihan wajib dilaksanakan yang merupakan program rutin dari Puskesmas. Ketidaklengkapan pencatatan buku KIA terkait dengan banyaknya tugas, tingginya jumlah kunjungan dan dari hasil observasi ketika sudah selesai jam kerja banyak petugas yang tidak menyelesaikan melengkapi buku KIA.

Supervisi kerja dalam upaya kelengkapan pencatatan buku KIA sebagian besar sudah berjalan baik. artinya tahapan dalam supervisi sudah dilakukan, namun masih banyak ditemukan ketidaklengkapan pencatatan buku KIA. Hasil pengamatan menunjukkan ada satu kegiatan supervisi yang tidak dilaksanakan oleh bidan yaitu menyampaikan kendala yang di hadapi sehingga bidan tidak teliti dalam melakukan pencatatan buku KIA kepada supervisor/ atasan/ koordinator Hal ini dapat disimpulkan ketika ada pelaksanaan supervisi bidan melaporkan atau menunjukkan buku KIA yang sudah lengkap, namun hasil penelitian ini menunjukkan kebalikannya. Ketidak lengkapan pencatatan buku KIA berdasarkan hasil pengamatan peneliti adalah beban kerja petugas, ketika kunjungan ibu hamil banyak dipuskesmas, banyak bidan yang hanya menulis informasi penting saja seperti perkembangan kesehatan ibu dan anak. Hal yang dianggap kurang penting dalam buku KIA oleh bidan kadang tidak dilengkapi.

Hasil penelitian ini didukung penelitian Siswiantari (2016) menemukan bahwa faktor terbesar dari ketidaklengkapan pencatatan buku KIA oleh bidan adalah bidan yang kurang sabar dalam pendokumentasian sehingga mengakibatkan 19 buku KIA tidak tercatat lembar anamneses $(37,26 \%)$ dan 16 buku tidak tercatat lembar pemeriksaan fisik (31,37\%). Pada penelitian lain, Kartika (2013) menemukan bahwa faktor ketidaklengkapan pencatatan juga disebabkan oleh bidan yang kurang sabar dan terburu-buru dalam mengisi buku KIA sehingga bidan juga menulis apa yang dianggap paling penting saja dalam mengisi item yang ada di buku KIA (N2, N3 dan N4). Sedangkan Cahyani, Rahayu Norma Yudhy Dharmawan, Dharminto (2016) menyimpulkan bahwa faktor ketidaklengkapan pencatatan buku KIA 
adalah masa kerja, ketrampilan, beban kerja, motivasi, dan penghargaan.

\section{SIMPULAN}

Berdasarkan hasil penelitian dan pembahasan di atas dari 65 responden maka dapat disimpulkan:

Kelengkapan pencatatan buku KIA di Puskesmas di Kota Kupang Provinsi Nusa Tenggara Timur sebagian besar tidak lengkap (52,3\%).

Pengetahuan bidan tentang kelengkapan pencatatan buku KIA di Puskesmas di Kota Kupang Provinsi Nusa Tenggara Timur sebagian besar kurang (78,5\%).

Sikap bidan dalam upaya kelengkapan pencatatan pencatatan buku KIA di Puskesmas di Kota Kupang Provinsi Nusa Tenggara Timur semua responden memiliki sikap positif (100,0\%).

Pelatihan bidan dalam upaya kelengkapan pencatatan buku KIA di Puskesmas di Kota Kupang Provinsi Nusa Tenggara Timur semua responden sudah mendapatkan pelatihan $(100,0 \%)$.

Supervisi bidan dalam upaya kelengkapan pencatatan buku KIA di Puskesmas di Kota Kupang Provinsi Nusa Tenggara Timur sudah berjalan baik (96,9\%).

\section{SARAN}

Dinas kesehatan kota kupang aagar meningkatkan bimbingan teknis dan monitoring terhadap pencatatan buku KIA.

Puskesmas mengadaakan review tentang pengisian buku KIA dan meningkatkan pengawasan terhadap nakes di puskesmas dan faskes diwilayah nya secara rutin.
Bidan Meningkatkan kepatuhan dalam melengkapi buku KIA mengingat manfaat dari buku KIA mengingat manfaat dari buku KIA sangat penting dalam memberikan pelayanan.

Peneliti selanjutnya agar mengembangkan penelitian ini dengan melakukan wawancara mendalam untuk mengetahui factor yang mempengaruhi ketidaklengkaaapan pencatatan buku KIA serta mencari upaya untuk meningkatkan kemampuan petugas dalam melengkapi pencatatan buku KIA.

\section{DAFTAR PUSTAKA}

Azwar. (2009). Sikap Manusia, Teori dan Pengukurannya. Yogyakarta: Pustaka Belajar.

Cahyani, Rahayu Norma Yudhy Dharmawan, Dharminto. (2016). Beberapa Faktor Yang Berhubungan Dengan Kelengkapan Pengisian Dan Pemanfaatan Data Pada Buku Kia Oleh Bidan Desa Di Kabupaten Sragen. JURNAL KESEHATAN MASYARAKAT (e-Journal) Volume 4, Nomor 4, Oktober 2016 (ISSN: 2356-3346) http://ejournals1.undip.ac.id/index.php/jkm

Dinas Kesehatan Kota Kupang. (2017). Profil Kesehatan 2016. Dinas Kesehatan Provinsi Nusa Tenggara Timur.

Departemen Kesehatan RI dan JICA.a (2009). Petunjuk Teknis Penggunaan Buku Kesehatan Ibu Dan Anak. Jakarta:

Departemen Kesehatan RI dan JICA.b (2015). Petunjuk Teknis Penggunaan 
Vol. 7 No. $2: 48$ - 63

Buku Kesehatan Ibu dan Anak. Jakarta: Departemen Kesehatan RI.

Hasanah, H. (2012). Petujuk Penggunaan Buku KIA Serta Manfaat Buku KIA. Yogyakata. Nuha Medika.

IBI. (2010). Manajemen Pelayanan Kebidanan Mandiri. Jakarta: Sari Husada.

Kartika, (2013). Fungsi Pemanfaatan Buku KIA terhadap Pengetahuan Kesehatan Ibu dan Anak pada Ibu. Kesmas, Jurnal Kesehatan Masyarakat Nasional Vol. 8, No. 8, Mei 2013.

Kementerian Kesehatan Republik Indonesia. (2017). Survei demografi dan Kesehatan Indonesia tahun 2017. Jakarta: Kementerian Kesehatan Republik Indonesia.

Mufdillah. (2012). Panduan Asuhan Kebidanan Ibu Hamil. Yogyakarta. Nuha Medika.

Niven. (2012). Psikologi Kesehatan Pengantar Untuk Perawat Dan Professional Kesehatan. Jakarta: Rineka Cipta.

Notoatmodjo, S. (2014). Ilmu Perilaku Kesehatan. Jakarta: PT Rineka Cipta.

Prawirohardjo, Sarwono. (2008). Ilmu Kebidanan. Jakarta: P.T Bina Pustaka.

Rante, A, Susilo W, Faikah. (2007). Studi deskriptif dan analisis faktor yang berpengaruh dalam tingkat pengetahuan KIA pada ibu di Puskesmas Cakaranegara Mataram. Jurnal Kesehatan Prima.

Siswiantari, Cahya Novita. (2016). Analisis Pendokumentasian Catatan Kesehatan Ibu Hamil pada Buku Kesehatan Ibu dan Anak (KIA) di Puskesmas
Kartasura. Skripsi. Universitas Muhammadiyah Surakarta.

Supanik. (2011). Pengaruh Pendidikan Kesehatan dalam Pengisian Buku Kesehatan Ibu dan Anak Terhadap Prilaku Bidan Tugas Belajar di Kabupaten Lamongan. Jurnal Kesehatan Masyarakat Nasional Vol. 8 No. 8 Mei 2011

Syafiq.A, Fikawati S. (2007). Kepemilikan Buku Kesehatan Ibu Dan Anak (KIA) dan Pelayanan KIA. Depok: Fakultas Kesehatan Masyarakat Universitas Indonesia.

Wawan, A. dan Dewi, M. (2011). Teori dan Pengukuran Pengetahuan, Sikap dan Perilaku Manusia. Yogyakarta: Nuha Medika.

Yuyun, S. (2015). Factors Related to the Completeness of Maternal and Child Health BookFilling by Midwives in Early Detection of High Risk Pregnancy in PrimaryHealthcare Centers in Banyumas District. Tesis MIKM UNDIP. 